\title{
Biomimetic materials: A review
}

\author{
Shetty $\mathbf{S}^{1}$, MK Manjunath ${ }^{2}$ \\ ${ }^{1}$ Dr Suneeth Shetty, Senior lecturer, ${ }^{2}$ Dr M.K Manjunath, Prof \& Head. Both are affiliated with Department of \\ Conservative Dentistry \& Endodontics, J.S.S Dental College \& Hospital, J.S.S University, Mysore Bangalore road, Sri \\ Shivarathreeshwara Nagara, Bannimantap, Mysuru, Karnataka 570015, India
}

Address for correspondence: Dr Suneeth Shetty, Email: s_suneeth@yahoo.com

\begin{abstract}
Biomimetics: The science of imitating nature is a growing multidisciplinary field, which is now leading to the fabrication of novel materials with remarkable mechanical properties. It is the study of biological structures, their functions and synthetic pathways emerging at the intersection between cellular biology, molecular biology, material sciences, dentistry and medicine. Bio meaning life and Memesis meaning imitation are derived from Greek words. Perceptions regarding the scope of biomimetics appear to vary widely depending upon the specialized discipline of the investigation. Biomimetics provides a new strategy that translates our knowledge of biological structures and functions and creates new synthetic pathways to mimic biological processes.
\end{abstract}

Key words: biomimetic, biocompatible, mimic, biomaterials

\section{Introduction}

In dental medicine the concept of Biomimetic Material is an increasingly applicable word especially in restorative dentistry. The term biomimetic suggests imitation of nature in other words the material should be in some way reproducing one or more natural phenomenon within a biological situation. It also implies that the material will be biocompatible i.e. biologically acceptable to and not rejected by adjacent vital tissue following placement. Such a material may cause low transient, inflammatory response, but it will not release chemical irritants into the vicinity. The secondary meaning of biomimetics refers to mimicking or recovery of the original tooth both in form as well as function. Biomimetic dentistry is a philosophy that teeth needing restoration should be rebuilt if possible to mimic clearly the form and the function of the original design[1].

Several research disciplines in dental medicine have evolved with the prospect to mimic oral structures. In clinical dentistry we are challenged to design and fabricate new biomaterials that can mimic the tooth both in form and function [2].

Manuscript received: $20^{\text {th }}$ Sept 2015

Reviewed: $30^{\text {th }}$ Sept 2015

Author Corrected: $14^{\text {th }}$ Oct 2015

Accepted for Publication: $20^{\text {th }}$ Oct 2015
The following materials can be considered as biomimetic

- Glass ionmer cements

- Calcium hydroxide

- Mineral trioxide aggregate

- Calcium phosphate

- Calcium sulphate

- Bioactive glass

- Emdogain

- Composites

- Ceramics

- Biodentine

\section{Glass Ionomer Cement}

The invention of glass ionomer cement in 1969 (first reported by Wilson and Kent in1971) resulted from basic studies on dental silicate cements where the phosphoric acid was replaced by organic chelating acids.

\section{Reinforced Glass Ionomers}

The design of the original glass ionomer cements was a hybrid formulation of silicate and polycarboxylate cements. The earliest commercial product was named using the acronym for the formulation and was called aluminosilicate polyacrylic acid (ASPA). 
Attempts to the further improve the strength of the glass ionomers led to the incorporation of metallic oxide and metal alloy fillers by Seed and Wilson in 1980,but these cements known as MIRACLE MIX had poor wear resistance. Later McLean and Gasser in 1985 overcame this problem by fusing silver particles onto the ionomer glass - 'CERMETS'

Thereby rendering better wear resistance, smoother surface radiopacity, but had poor esthetics.

Further development led to the introduction of RESIN MODIFIED GLASS IONOMER OR HYBRID CEMENTS by

Mathis and Ferracane in 1989.In these cements the glass ionomers were reinforced by incorporation of resins and the fundamental acid base curing reaction is supplemented by a second polymerization curing process, which is initiated by light (DUALCURE) or both i.e. light and chemical (TRICURE), HEMA (Hydroxy Ethyl Metharylate) is the hydrophilic ionomer used in the liquid component of resin modified glass ionomers, so that the final restorations have 4.5-6\% resin.

These materials have increased working time due to the provision of COMMAND SET and have shown good adaptation and adhesion properties with acceptable fluoride releasing capacity. They had the disadvantages of shrinkage due to polymerization and limited depth of cure.

Continued evolution produced the Polyacid modified resin composites (compomers- a misnomer), these materials were introduced in 1993 from manufactures efforts to improve and combine the best properties of glass ionomers and composite resins. The earliest term for these systems was 'isosit' (combining the terms ionomers and composite), but it was trademarked by a single manufactures. The industry adopted the alternative arrangement of combined terms (composite and ionomers) which is now known as POLYACID MODIFIED COMPOSITE RESINS. [7].

These composite resins were modified by adding polyacrylic acid into it. After the composite is polymerized, the water from the saliva initiates an acid base reaction between the polyacrylic acid and the glass. These materials have been found to have properties intermediate to that of glass ionomers. Bond strength has been found to be equal to conventional composites. These materials are mainly intended for class III/V cavities as an alternative to glass ionomers or composites.

A special temporary filling material has been fabricated from glass ionomer for use in the atraumatic restorative treatment (ART) technique. Developed in the mid 1990's for regions of underdeveloped countries where routine treatment was not possible, untrained dental personnel could use ART to lessen the progression of carious lesions until the patient could access dental facilities. An ART restoration is based on self-cured version of conventional glass-ionomer that is mixed as a powder with liquid and is capable of relatively high fluoride release. Since ART development, evidence has been accumulated that these are useful in numerous dental situations [10].

Robert's developed another type of glass-ionomer called 'GIOMER' in 1998. These are hybrids of glass ionomers and composite resins, where pre reacted glass ionomer particles (PRG) are added into them. Fluroamino-silicate glass pre reacted with polyacrylic acid containing either fully reacted glass particles or surface reacted glass particles are incorporated. These materials are indicated for root caries lesions, noncarious cervical lesions, class V lesions but are not truly competitive with composites as permanent filling materials in posteriors.

\section{Composition}

Powder

- $\quad$ Silica $\left(\mathrm{SiO}_{2}\right)$

$30.1 \%$

- $\quad$ Alumina (Al2O3) $19.9 \%$

- Aluminium fluoride $\left(\mathrm{ALF}_{3}\right)$ $2.6 \%$

- Calcium fluoride $\left(\mathrm{CaF}_{2}\right.$ $34.5 \%$

- $\quad$ Sodium fluoride $(\mathrm{NaF})$ $3.7 \%$

- Aluminium phosphate $\left(\mathrm{Al}_{3} \mathrm{Po}_{4}\right)$ $10 \%$

\section{Modifications in Powder}

Some of the modifications of powder are:

- Dried Polyacrylic Acid (Anhydrous GIC)

- Silver Tin Alloy (Miracle mix)

- Silver Palladium/Titanium mix (Cermet Cement)

- BISGMA, TEGMA and HEMA (Light Dual Cure)

Variations in Glass Composition: Barium and Lanthanum can be added to the glass to impart radio 
opacity to the cement. Glasses may be modified by phase dispersion by adding droplets of corundum, rutile or badeleyite to improve the mechanical properties.

\section{Liquid}

The percentage composition of glass ionomer liquid is

- POLYACRYLIC ACID+ITAIONIC ACID $\rightarrow 40$ $50 \%$

- TARTARIC ACID $\rightarrow 15 \%$

- WATER $\rightarrow 30 \%$

\section{Classification of Glass Ionomer Cements}

1. Wilson and McLean traditionally classified glass ionomers based on their usage into

- Type 1: for luting

Uses: cementation of crowns, bridges, inlays etc

- $\quad$ Type 2: for restorative

○ Type 2.1 -for aesthetic restorations

Uses - class III, class V cavities, tunnel restorations

○ Type 2.2 - for restorations requiring reinforcement

Uses - core buildups

- $\quad$ Type 3: for liner and base applications

Uses: Low powder: liquid ratio for liners, High powder: liquid ratios for bases beneath amalgam and composite

2. More recently, one more classification for glass ionomers has been reported

Type I- Luting

Type II- Restorations

Type III- Liners and bases

Type IV- fissure sealants

Type V-Orthodontic cementation

Type VI- Core build up

Type VII- Intermediate restorations

Type VIII- Atraumatic Restorative Techniques (for anteriors)

Type IX- Atrumatic Restorative Techniques (for posteriors)

Chemistry of Setting: When the powder and liquid are mixed to form a paste, the acid etches the surface of the glass particles and calcium, aluminum, sodium and fluorine ions are leached into the aqueous medium.

The polyacrylic acid chains are cross-linked by the calcium ions within the next 24 hours. Sodium and fluorine ions do not participate in the cross linking of the cement. Some of the sodium ions may replace the hydrogen ions of carboxylic groups, whereas the remaining ions are dispersed uniformly within the set cement along with fluorine ions. The cross linked phase becomes hydrated over time with the same water used for mixing. This process is called maturation. The unreacted portion of glass particles are sheathed by a silica gel that develops during the removal of cations from the surface of the particles.

Water plays a critical role in the setting.It serves as the reaction medium initially and then slowly hydrates the cross linked matrix, thereby yielding a stable gel structure that is stronger and less susceptible to moisture. If freshly mixed cements are exposed to ambient air without any protective covering, the surface will craze and crack as a result of desiccation.

\section{Physical Properties of Glass Ionomers [10]}

Glass ionomers are rapidly setting cements with setting times in the range of 3-8 minutes. Working time should not exceed $45 \mathrm{~s}$. They have high compressive strengths, which may range from 200-400Mpa but are weak in flexure [5-40Mpa].

Aesthetics: The glass component of glass ionomers provides the translucency for the material glass ionomers provide the translucency for the material.

Adhesion: Glass ionomers have the important property of permanently adhering to the untreated enamel and dentin. They also bond to the polar substitutes like base metals. $80 \%$ of the bond strength is developed in the first $15 \mathrm{~min}$ of cement application and for this purpose cement should be applied immediately after mixing without delay.

Dissolution and Erosion: Chemical erosion by acids generated by plaque or external agents like food and beverages has been found to be less for glass ionomers than other cements.

Marginal Adaptation and Leakage: The co-efficient of thermal expansion of conventional glass ionomer cements is close to that of dentinal hard tissue and has been citied as a significant reason for the good margin adaptation of glass ionomer restorations.

Coefficient of Thermal Expansion: Glass ionomer has a linear co-efficient of thermal expansion $\left(10-11 \times 10^{-6}\right)$, similar to that of tooth structure $\left(11.4 \times 10^{-6}\right)$. Under 
wet conditions, glass ionomers tend to maintain their original dimensions when heated.

Biocompatibility: Freshly mixed glass ionomer cements are acidic ( $\mathrm{pH}$ 0.9-1.6) and it rises rapidly within the first $20 \mathrm{~min}$ to reach a ph of 5.5-6 as the polysalt formation takes place.

Fluoride Release and Rechargeability: One unique feature of glass ionomer cements is the ability to release fluoride into the mouth for prolonged periods of time. The fluoride ions do not take part in the setting reaction but remain within the matrix of the cement They can also absorb fluorides applied topically in the oral cavity.

\section{Disadvantages}

- Susceptible to dehydration over lifeline

- Sensitivity to moisture at placement.

- Poor abrasion resistance

- Average esthetics

- Less Tensile strength than composites

- Technique sensitive powder to liquid ratio and mixing

\section{Mechanism of Action}

\section{$\mathrm{Ca}(\mathrm{OH})_{2}$ induced mineralization}

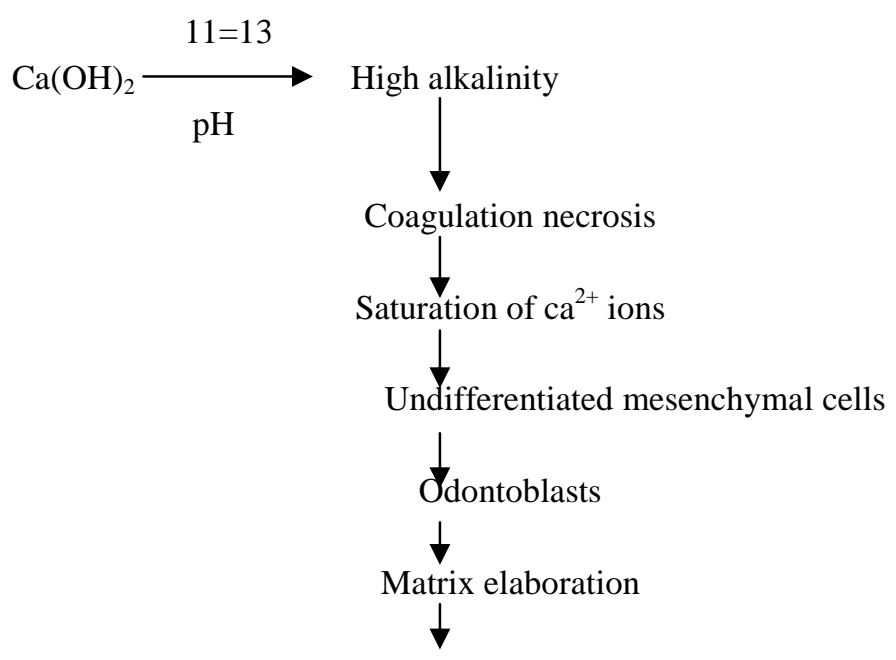

This matrix contains acid mucopolysaccharides and glycoprotein<smiles></smiles>

\section{Classification [14]}

\section{Setting materials eg Dycal, Reocap, Procal etc.}

Non setting materials: $\mathrm{Ca}(\mathrm{OH})_{2}$ containing pastes can be classified according to whether they are setting or non-setting materials.
- Less color stable than resins

- Contraindicated for class IV or other stress bearing restorations.

\section{Calcium Hydroxide}

Calcium hydroxide was introduced to dentistry by Hermann at the beginning of the $20^{\text {th }}$ century and since then it has been widely used in endodontics.It is a strong alkaline substance with a $\mathrm{pH}$ of approximately 12.5 and has various biologic properties that prompted it's use in several clinical situations. Its dental use relates chiefly to its antibacterial properties and the ability to induce repair and to stimulate hard tissue formation. The main benefit of calcium hydroxide as an intracanal medicament lies in the bacterial effects conferred by its high $\mathrm{pH}$ as many endodontic microorganisms are unable to survive in the highly alkaline environmental provided by calcium hydroxide. ${ }^{13}$ 
2. Unpredictability of apical closure.

3. Difficulty in patient follow up.

4. Delayed treatment.

5. Canal is susceptible to fracture during treatment.

6. $\mathrm{Ca}(\mathrm{OH})_{2}$ doesn't adhere to dentin and lack the ability to seal. Tunnel detects in dentin bridges can act as pathways for microleakage.

\section{Mineral Trioxide Aggregate:}

MTA is a new material developed for endodontics that appears to be a significant improvement over other materials. Ever since it's introduction by Torabinejad and colleagues in 1993 it has been used in both surgical and nonsurgical applications. It is the first restorative material that consistently allows for the overgrowth of cementum and it may facilitate the regeneration of the periodontal ligament. Thus it may be termed as 'Biomimetic Material'.

\section{Advantages [19, 20]}

1. Resistance to marginal leakage reduces bacterial migration.

2. Least toxicity of all the filling materials.

3. Excellent biocompatibility.

4. Hydrophilic sets in the presence of moisture. Moisture contamination is not an issue.

5. Negligible Solubility

6. Super Sealing ability

7. Sufficient compressive strength to allow condensation of amalgam when it is used as pulp capping agent.

8. Reasonably radio opaque.

9. Non resorbable.

\section{Disadvantages}

1. Difficult to manipulate.

2. Prolonged setting time.

3. Dissolves in acidic $\mathrm{pH}$.

\section{Properties [23]}

1. MTA has a pH of 10.2 initially and has a $\mathrm{pH}$ of 12.5 , 3hours after mixing. This may impart some antimicrobial properties.

2. The material has low solubility.

3. It has a radiopacity slightly greater than that of dentin.

4. MTA is found to be non-mutagenic and it is less cytotoxic than other root end filling materials, it is biocompatible.

5. Its water based chemistry allows normal setting in the presence of moisture and blood.
6. Resistance to the marginal leakage and reduction of bacterial migration.

7. Normal healing response without inflammation.

8. The setting time is approximately 3 hours.

\section{Types}

a. MTA is supplied as a grey powder ProRoot MTA .The manufacturer recommends that it should be mixed with sterile water into a thick grainy paste. It can be mixed with anaesthetic or other sterile liquids.

b. Tooth coloured white ProRoot MTA is also available with easy clinical manipulations.

It was introduced in 2002 to eliminate the grayness of the original MTA

\section{Composition}

Mineral trioxide aggregate is a powder consisting of fine hydrophilic particles of

1. Tricalcium silicate $\left(\mathrm{CaSiO}_{4}\right)$

2. Bismuth oxide powder has been added to make the powder radio opaque $\left(\mathrm{Bi}_{2} \mathrm{O}_{3}\right)$

3. Dicalcium Silicate $\left(2 \mathrm{CaOSiO}_{2}\right)$

4. Tricalcium Aluminate $\left(3 \mathrm{CaOAL}_{2} \mathrm{O}_{3}\right)$

5. Calcium Sulphate $\left(\mathrm{CaSO}_{4}\right)$

6. Tetar calcium alumino ferrite $\left(4 \mathrm{CaOAl}_{2} \mathrm{O}_{3} \mathrm{FeO}_{3}\right)$

7. Tricalcium Oxide

8. Silicate Oxide and an amorphous structure consisting of $33 \% \mathrm{Ca}, 49 \%$ Phosphate, $2 \%$ carbon, $3 \%$ chloride and $6 \%$ Silica.

Electron probe microanalysis of MTA powder showed that calcium and phosphorus are the main ions present. Hydration of the powder results in a colloidal gel that solidifies in 3hours.

Mechanism of Action: Studies have shown that pulp capping with mineral trioxide aggregate induces cytological and functional changes in pulpal cells resulting in formation of fibrodentine and reparative dentine at the surface of mechanically exposed pulp. As a pulp capping agent MTA offered a biologically active substrate for cell attachment increased levels of alkaline phosphatase, Osteocalcin and interleukin-6 and interleukin-8.In vitro studies have demonstrated that the antibacterial effects of MTA are comparable to $\mathrm{Ca}\left(\mathrm{OH}_{2}\right.$ and it is more effective in preventing bacterial microleakage.

The ability of MTA to induce the formation of dentine bridge may be due to its excellent sealing ability and biocompatibility. MTA can induce cytokine release 
from bone cells and can allow attachment osteoblasts in the form of monolayer.

MTA possibly activates cementoblasts to produce matrix for cementum formation. Studies suggest that MTA permits cementoblast attachment and growth and the production of mineralized matrix gene and protein expression.

Regardless of its origin, cementoblasts are the cells responsible for cementum production and regeneration, concluding that MTA are cemtoconductive materials.

\section{Clinical Applications of Mineral Trioxide Aggregate $[24,27,28]$}

It has been used in both surgical and non-surgical applications.

1) Direct pulp capping and pulpotomy

2) Apexification

3) Repair of root perforations( surgically and nonsurgically)

a) Lateral perforation.

b) Furcation perforation

c) Strip perforation.

4) Root-end filling

5) MTA can also be used for repair of perforation as a consequence of internal resorption.

\section{Calcium Phosphate}

Researchers have shown that calcium phosphate ceramic biomaterial are effective for a variety of

- Restorative

- Preservative clinical applications

Calcium phosphate ceramics such as hydroxyapatite and beta tricalcium phosphate possess a mineral composition very close to that of normal bone, biphasic calcium phosphate ceramics consist of both beta tricalcium phosphate and hydroxyapatite. Their biocompatibility makes them successful bone substitute studies

have shown that they have osteoconductive potential and thus be termed as a biomimetic material.

\section{Emerging dental applications}

- To fill oversized osteotomies for implants

- Craniofacial reconstructions

- Interpositional grafting procedures

- As a coating around the metallic implants

\section{Calcium Sulfate}

In the last decade calcium sulfate has been introduced into periodontology and implantology and in endodontics for the treatment of bone lesions. It can be used both as a barrier and hemostatic material in perforation management. Calcium sulfate creates a tamponade effect mechanically plugging the vascular channels once it sets. It is remarkably biocompatible does not promote inflammation and is bioresorbable in 2-4 weeks. The material is syringed through tooth in the osseous using a microtube deliver system. During the placement of calcium sulfate it will fill the osseous defect and a portion of the space within the root defect. Calcium sulfate rapidly sets brick hard, is easily flushed to the external root surface with selected ultrasonic finishing instruments

\section{Bioactive glass:}

Bioactive glass (BAGs) first introduced by Hench et al are surface active glasses that bond chemically to bone materials. They are non-bone graft materials. These bioactive glasses contain different ratios of $\mathrm{Na}_{2} \mathrm{O}$ (24.5\%), $\mathrm{CaO}(24.5 \%) \mathrm{P}_{2} \mathrm{O}_{5}-\mathrm{SiO}_{2}(45 \%)$. The bonding at BAGs to living bones is achieved through a bone like apatite layer forming on their surface in the body environment owing to their strong bond with living bone, BAGs have been used as a bone substitute materials in different clinical conditions [31].

There are currently two commercially available glasses for the application in bone sites, Bioglass with a particle size of $300-355 \mu \mathrm{m}$. they are $100 \%$ synthetic bone restorative or regenerative materials.

\section{Enamel Matrix Derivative (EMD)}

Enamel matrix proteins secreted by Hertwig's epithelial sheath play an important role in cementogenesis and in the development of the periodontal attachment apparatus Animal experiment studies showed that an acidic extract from porcine enamel matrix containing a hydrophobic protein assembly of amelogenin had the capacity to induce regeneration of all periodontal tissues. The purified acidic extract is called enamel matrix derivative.

The enamel matrix is composed of a number of proteins

- Amelagenin

- Amelin

- Enamelin

○ Tuft protein

- Amelogenins - 90\%

\section{Bone morphogenetic proteins [33]:}


In 1964, Marshal Urist discovered that bone which had been demineralized and dried into a powder could be implanted into the muscle of a rabbit and stimulate the growth of a new bone. Urist and collaborators later determined that the active component with proteinaceous and dubbed it bone morphogenetic proteins (BMP).

There are at least 15 BMP like molecules

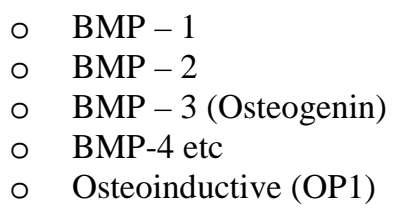

Eight BMPs namely BMP-1-7 and osteogenic protein have so far been cloned and expressed. A BMP like activity which induce bone formation is also present in dentin. The precise BMPs in dentin have not been identified. It is likely that BMPs play a role in dentinogenesis.

\section{Clinical applications}

1. Direct pulp capping

2. Pulpotomy

3. Guided bone regeneration

4. Furcation repair

5. Dental implants

\section{Resin based composites}

These composites include

1. Smart composites

2. Ormocers

3. Ceromers

Smart materials: Tooth colored restoratives which are cariostatic in nature by their inherent ability to leach fluoride are referred to as smart fluorides.

\section{Classification}

Passive smart materials

These are materials that release ions into the oral cavity continuously with or without the necessity to prevent caries

Eg. Glass ionomer cement

Resin modified glass ionomer

Ceromers

Active smart material: These are materials, which can react favorably when there is a hazardous variation in the environment surrounding the restoration and prevent caries.

\section{Ex. Smart composite}

Smart composites: A new approach in restorative dentistry was the introduction of an ion releasing composite material in 1998. Ariston PHC was presented by its manufacturers as an alkaline glass filled ion releasing amalgam substitute.

It is based on a new developed alkaline glass which aims at reducing secondary caries, reducing demineralization and buffering acid produced by microorganisms, when the $\mathrm{pH}$ around the restorative material falls below 5.5, the material releases hydroxyl, calcium and fluoride ions.

Mode of supply: It is available in unit dose capsules (cavifils) and in syringes. Fluoride release from this material is lower than conventional glass ionomer cements but more than composites.

Table 1: Composition of SMART materials

\begin{tabular}{|l|l|}
\hline Resin & Filler \\
\hline BISGMA & $\begin{array}{l}\text { Alkaline calcium silicate } \\
\text { glass }\end{array}$ \\
\hline UDMA & Ba-Al-F silicate glass \\
\hline TGEMA & Ytterbium fluoride \\
\hline & Silicon dioxide \\
\hline
\end{tabular}

\section{Ormocers}

It is the acronym of organically modified ceramic. It was developed by Fraunhofer institute for silicate research, Wurzburg in co-operation with partners form the dental industry in 1998.

They are new type of material which chemically are methacrylate substituted alkoxysiyl. New multifunctional urethane and thioether (meth) acrylate alkoxy as sol-gel precursors have been developed for preparation of inorganic -organic co-polymers composites.

\section{Composition}

- Ormocer matrix - Ceramic polysiloxane (siliconoxygen chain)

- Zirconium and glass fillers (1-1.5 $\mu \mathrm{m}$ in size)

- Coupling agents

Eg. Admira $\rightarrow$ Voco

Definite $\rightarrow$ Deguassa

Advantages 
- Biocompatible

- Reduced polymerization shrinkage

- High abrasion resistance

- Esthetics

- Anticaries property

It is one of the most promising alternatives to Amalgam

\section{CEROMERS $\rightarrow$ Ceramic optimized polymers}

They are specific combination of the latest in ceramic filler technology and advanced polymer chemistry which provide enhanced function and esthetics.

They are composed of specially developed and conditioned homogenous three dimensional fine particle ceramic fillers $(0.04-1 \mathrm{~mm})$ of submicrometer size which are densely packed (approx $80 \%$ in weight) and embedded in an advanced organic matrix with optimum light and heat curing potential.

$$
\text { e.g Targis / Vectris - Ivoclar }
$$

\section{Composition}

○ Barium glass

- Spheroidal mixed oxide

- Ytterbium trifluroide

- BIS-GMA

- Urethane dimethacrylate

\section{Disadvantages of Dental Ceramics}

1. BRITTLENESS:

2. TECHNIQUE SENSITIVE:

3. HIGH COST:

4. WEAR OF NATURAL TEETH:

5. DIFFICULT TO REPAIR INTRAORALLY

\section{Properties of Dental Ceramics}

1. The compressive strength of dental ceramics is high(50000psi), but tensile(5000psi) and shear strengths (16000psi) are low surface defects are responsible for low tensile strengths while low shear strengths are due to lack of ductility.

2. They are brittle due to their low tensile strengths and lack of ductility, stress concentration in the area of voids, defects, cracks etc can lead to fracture propagation

3. They have an elastic modulus of $10 \times 10^{6}$ psi.The amount of shrinkage will depend on the average pore size,for low fusing it is approx $14 \%$ and for high fusing it is $11.5 \%$.

4. The density of ceramics is around $2.45 \mathrm{~g} / \mathrm{cm}^{3}$ and varies according to the porosity of the material.
Advantages
1. Durable esthetic quality
2. High abrasion resistance
3. High stability
4. Excellent polishability
5. Fluoride release

Table 2: indications \& Contraindications of CEROMERS

\begin{tabular}{|l|l|}
\hline Indications & Contraindications \\
\hline $\begin{array}{l}\text { Single unit metal free } \\
\text { full coverage }\end{array}$ & $\begin{array}{l}\text { When field isolation cannot } \\
\text { be maintained }\end{array}$ \\
\hline $\begin{array}{l}\text { Metal free implant } \\
\text { super structures }\end{array}$ & $\begin{array}{l}\text { When preparations are } \\
\text { extending subgingivally }\end{array}$ \\
\hline Jacket crowns & \\
\hline Inlays and onlays & \\
\hline
\end{tabular}

\section{Ceramics}

Dental ceramics with their unmatched esthetics, excellent biocompatibility and good strength make them one of the most promising materials in restorative dentistry and with the recent advances to overcome their few short comings can be termed as 'biomimetic materials.'

5. They have low thermal conductivity $\left(0.0050^{\circ} \mathrm{c} / \mathrm{cm}\right)$ and thermal diffusivity $\left(0.64 \mathrm{~mm} / \mathrm{sec}^{2}\right)$.this makes them good insulators in the oral cavity.

6. Ceramics are extremely hard with a knoop hardess of 460 and can cause wear of the opposing natural teeth or other restorative materials

7. They have a linear coefficient of thermal expansion $12 \times 10^{-6} / \mathrm{C}$

8. Their solubility is extremely low and probably the most resistant material to attack by oral fluids.

9. It has excellent biocompatibility as it is inert, chemically stable and corrosion resistant, it's ability to attain highly smoothed and polished surface does not allow plaque accumulation and hence is condusive to gingival health.

10. They have excellent esthetics closely matching that of natural enamel, it is available in a variety of shades with stains and color modifiers available to produce the exact match.

\section{Classification}

1. Sintered all ceramic materials.

- Alumina based ceramics eg. Hi-ceram

- Leucite-based ceramics eq.Optec HP

2. CASTABLE CERAMICS

3. PRESSABLE CERAMICS

- Leucite-reinforced 
- Lithium dislocate reinforced Eg.IPS Empress 1, IPS Empress 2

4. Infiltrated/slip cast ceramics

- Alumina-based ceramics

- $\quad$ Spinel based ceramics Eg. InCeram ad InCeram spinel

5. Machinable Ceramics

- CAD-CAM systems

- Copy-milling systems.

Eg.Cerec Vitablocs Mark 1, Cerec Vitablocs Mark

2, DICOR MGC

\section{Biodentine $^{\mathrm{TM}}$}

Was developed by Septodont's Research Group, Several years of active and collaborative research between Septodont and several universities led to a new calcium-silicate based formulation, which is suitable as a dentin replacement material whenever original dentin is damaged, thus these materials are termed as biomimetic

\section{Composition}

\section{Powder}

Tri-calcium Silicate $\left(\mathrm{C}_{3} \mathrm{~S}\right)$

Di-calcium Silicate $\left(\mathrm{C}_{2} \mathrm{~S}\right)$

Main core material

Calcium Carbonate and Oxide

Second core material

Iron Oxide

Filler

Zirconium Oxide

Shade

Radiopacifier

\section{Liquid}

Calcium chloride

Hydrosoluble polymer

\section{Accelerator}

Water reducing agent

\section{Setting Reaction [41]}

The calcium silicate has the ability to interact with water leading to the setting and hardening of the cement. This is a hydration of the tricalcium silicate $\left(3 \mathrm{CaO} \cdot \mathrm{SiO}_{2}=\mathrm{C}_{3} \mathrm{~S}\right)$ which produces a hydrated calcium silicate gel (CSH gel) and calcium hydroxide $(\mathrm{Ca}$ $\left.(\mathrm{OH})_{2}\right)$.

\section{Clinical Application}

\section{Preservation of pulp vitality}

Absence of post operative sensitivity: High biocompatibility reducing the risk of pulp or tissue reaction.
Bioactive: remineralization of dentine for unique pulp healing properties

\section{Prevention of clinical failures}

Long lasting sealing properties: mineral tags in the dentine tubules combined with high dimensional stability over time. Less risk of bacterial percolation: outstanding microleakage resistance

\section{Ultimate dentinal substitute}

Easy handling for optimized clinical use.

Superior radiopacity for short and long term follow up.

\section{Conclusion}

Biomimetic materials attempts to repair the damaged living tissue, using or promoting natural mechanisms of growth. This method provides remarkable possibilities well beyond the traditional mode of treatments in almost all fields of dentistry including preventive, restorative, periodontal and reconstructive surgery. It is hoped that further research will extend the potential of these biomimetic materials, although it is unlikely that there will ever be a single universal material.

Funding: Nil,Conflict of interest: None. Permission of IRB: Yes

\section{References}

1. P Ram Chandra Rao. Biomimetics.J Biomed Mater Res 2003;28(4):657-676.

2. Slavkin HC. Biomimetics: replacing body parts is no longer science fiction. J Am Dent Assoc. 1996 Aug;127(8):1254-7.

3. Magne P, Douglas WH. Rationalization of esthetic restorative dentistry based on biomimetics. J Esthet Dent. 1999;11(1):5-15.

4. National instiute of dental and craniofacial reasearch. Biomimetic and tissue engineering. National Institutes of Health,2002.

5. Ratner BD. Replacing and renewing: synthetic materials, biomimetics, and tissue engineering in implant dentistry. J Dent Educ. 2001 Dec;65(12):13407.

6. Willson A.D. Mclean J.W, Glass ionomer cements . $1^{\text {st }}$ edition.quintessence publishing company 1988. 
7. Theodore Roberson,Harold O Heyman, Edward J Swift, sturdevents art and science of operative dentistry $5^{\text {th }}$ edition,Mosby; 2006.

8. Anusavice K.J Philips Science of dental material $11^{\text {th }}$ edition saunders; 2004.

9. Mount GJ, An atlas of glass ionomer cements- A clinicians guide $1^{\text {st }}$ edition BC decker Inc;1990.

10. Alber HF, Tooth colored restoratives $9^{\mathrm{TH}}$ edition.B.C Decker Inc;2007.

11.Foreman PC, Barnes IE. Review of calcium hydroxide. Int Endod J. 1990 Nov;23(6):283-97.

12. Ingle, Bakland,endodontics $\quad 6^{\text {th }}$ edition,Elsevier,2004.

13. Stephan Cochen,Richard C burns,pathways of pulp, $9^{\text {th }}$ edition :mosby:2002.

14. Sheehy EC, Roberts GJ. Use of calcium hydroxide for apical barrier formation and healing in non-vital immature permanent teeth: a review. Br Dent J. 1997 Oct $11 ; 183(7): 241-6$.

15. Morse DR, O'Larnic J, Yesilsoy C. Apexification: review of the literature. Quintessence Int. 1990 Jul;21(7):589-98.

16. Sarkar NK, Caicedo R, Ritwik P, Moiseyeva R, Kawashima I. Physicochemical basis of the biologic properties of mineral trioxide aggregate. J Endod. 2005 Feb;31(2):97-100.

17. Hamad HA, Tordik PA, McClanahan SB. Furcation perforation repair comparing gray and white MTA: a dye extraction study. J Endod. 2006 Apr;32(4):337-40.

18. Asgary et al, Chemical differences between grey and white MTA,2005;31(1) 101-103

19. Rafter M, Baker M, Alves M, Daniel J, Remeikis N. Evaluation of healing with use of an internal matrix to repair furcation perforations. Int Endod J. 2002 Sep;35(9):775-83.

20. Abedi H R, Torabinejad M, the use of MTA as direct pulp capping agent, J Endod 1996;22:199-204
21. Thomas pittford, Torabinejad M , Use of MTA for furcation repair, Oral Surg Oral Med Oral Pathol 1995;79(6) :756-762.

22. Sluyk SR, Moon PC, Hartwell GR. Evaluation of setting properties and retention characteristics of mineral trioxide aggregate when used as a furcation perforation repair material. J Endod. 1998 Nov;24(11):768-71.

23. Bargholz C. Perforation repair with mineral trioxide aggregate: a modified matrix concept. Int Endod J. 2005 Jan;38(1):59-69.

24. Lemon RR. Nonsurgical repair of perforation defects. Internal matrix concept. Dent Clin North Am. 1992 Apr;36(2):439-57.

25. Chau JY, Hutter JW, Mork TO, Nicoll BK. An in vitro study of furcation perforation repair using calcium phosphate cement. J Endod. 1997 Sep;23(9):588-92.

26. Hemamalathi J and Paramaeswaran A, Bioceramics in clinical dentistry,JIDA 2001;72:228-231

27. Xu HH, Carey LE, Simon CG Jr, Takagi S, Chow LC. Premixed calcium phosphate cements: synthesis, physical properties, and cell cytotoxicity. Dent Mater. 2007 Apr;23(4):433-41. Epub 2006 May 6.

28. Alhadainy HA. Root perforations. A review of literature. Oral Surg Oral Med Oral Pathol. 1994 Sep;78(3):368-74.

29. Yli-Urpo H, Närhi T, Söderling E. Antimicrobial effects of glass ionomer cements containing bioactive glass (S53P4) on oral micro-organisms in vitro. Acta Odontol Scand. 2003 Aug;61(4):241-6.

30. Aichelmann-Reidy ME, Yukna RA. Bone replacement grafts. The bone substitutes. Dent Clin North Am. 1998 Jul;42(3):491-503.

31.Salako N, Joseph B, Ritwik P, Salonen J, John $\mathrm{P}$, Junaid TA. Comparison of bioactive glass, mineral trioxide aggregate, ferric sulfate, and formocresol as pulpotomy agents in rat molar. Dent Traumatol. 2003 Dec;19(6):314-20.

32. Trope M. Clinical management of the avulsed tooth: present strategies and future directions. Dent Traumatol. 2002 Feb;18(1):1-11. 
33. Azari K, Doctor JS, Doll BA, Hollinger JO. Bone morphogenetic proteins: a review for cranial and maxillofacial surgery. Oral Maxillofac Surg Clin North Am. 2002 Feb;14(1):1-14.

34. Sunico MC, Shinkai K, Katoh Y. Two-year clinical performance of occlusal and cervical giomer restorations. Oper Dent. 2005 May-Jun;30(3):282-9.

35.Anusavice KJ. Buonocore Memorial Lecture. Materials of

the future: preservative or restorative? Oper Dent. 1998 Jul-Aug;23(4):162-7.

36. Xu X, Burgess JO. Compressive strength, fluoride release and recharge of fluoride-releasing materials. Biomaterials. 2003 Jun;24(14):2451-61.

37. Craig RG and powers, Restorative Dental Materials $12^{\text {th }}$ edition, Mosby;2006:443-447
38. V . Shama Bhat, B.T Nandish, Science of Dental Materials, $1^{\text {st }}$ edition, 2006

39. Nakashima M, Akamine A. The application of tissue engineering to regeneration of pulp and dentin in endodontics. J Endod. 2005 Oct;31(10):711-8.

40. About I, Laurent P, Tecles O. Bioactivity of Biodentine $^{\mathrm{TM}}$ a CA3SiO5-based Dentine Substitute. Oral session. IADR Congress July 2010, Barcelona, Spain.

41. Tran V, Pradelle N, Colon P. Micro leakage of a new restorative calcium based cement (Biodentine ${ }^{\circledR}$ ) Oralpresentation, mentioned in the "Biodentine publications and communications 2005-2010" by Septodont (Dec. 2012), page 64.

\section{How to cite this article?}

Shetty S, MK Manjunath. Biomimetic materials: A review. Int J Med Res Rev 2015;3(9):1026-1036. doi: 10.17511/ijmrr.2015.i9.189. 